\title{
La memoria histórica en los procesos de acompañamiento pastoral a personas en situación de desplazamiento
}

\author{
Olga CONSUElo VÉLEZ* \\ Pontificia Universidad Javeriana \\ ocvelez@javeriana.edu.co
}

ANDRÉS RODRÍGUEZ, OAR ${ }^{* * *}$

Universidad Universitaria Agustiniana

frgarohe@hotmail.com

\author{
ÁNGELA MARÍA SIERRA* \\ Pontificia Universidad Javeriana \\ angela.sierra@javeriana.edu.co
}

\author{
SUSANA BECERRA ${ }^{* * * *}$ \\ Pontificia Universidad Javeriana
}

sbecerra@javeriana.edu.co

\section{Resumen}

En los procesos sociopolíticos de superación de los conflictos armados, la recuperación de la Memoria histórica está ocupando un lugar central debido al papel que está juega para una efectiva reconciliación donde la verdad, la reparación y el perdón forman parte de ese proceso. La experiencia cristiana, como comunidad de memoria tiene mucho que aportar en la medida que articule la reflexión crítica sobre qué memoria, desde dónde, desde quiénes; con el potencial liberador del Dios que se pone del lado de las víctimas y desde ellas no deja que se olvide su dolor sino que busca transformarlo. Además incorporar la perspectiva de género, permite reconocer las diferencias genéricas que influyen en la recuperación de la memoria histórica. Mostrar la relevancia de estas articulaciones, es el propósito de este artículo con la invitación a transformar la pastoral urbana que pretende acompañar a las personas en situación de desplazamiento.

Palabras claves: Memoria, género, víctimas, desplazamiento, pastoral urbana.

\section{The historical memory in the process of pastoral support to displaced persons}

\begin{abstract}
In socio-political processes of overcoming armed conflict, the Historical Memory is taking a central point because of the role it plays for effective reconciliation where "truth, reparation and forgiveness" are part of that process. Christian experience, as memory community has much to contribute to articulate the critical reflection about what memory, from where, from whom; with the liberating potential of the God who takes the side of the victims and doesn't allow to forget them neither their pain and seeks transformation. Besides, incorporate the gender perspective, allow to recognize the gender differences and their influences in the recovery of historical memory. Show the relevance of these articulations is the purpose of this article with an invitation to transform urban pastoral in order to support displaced people.
\end{abstract}

Key Words: Memory, gender, victims, displacement, urban pastoral.

* Doctora en Teología. Profesora titular de la Facultad de Teología en la Pontificia Universidad Javeriana (Colombia). Es autora del libro El método teológico. Fundamentos, especializaciones, enfoques (2008).

** Magister en Teología. Profesora asistente de la Facultad de Teología de la Pontificia Universidad Javeriana (Colombia). Es autora del libro Unidad conyugal, esperanza para la familia (2007).

*** Magister en Teología. Decano de la Facultad de Humanidades de la Universidad Universitaria Agustiniana (Colombia).

**** Magister en Teología. Profesora asistente de la Facultad de Teología de la Pontificia Universidad Javeriana (Colombia). Es autora del libro El Arte de reinventar la vida, Una mirada de Género (2012).

Recibido: 15/Junio/2015 - Aceptado: 20/Julio/2015 


\section{Introducción}

Ante el conflicto armado colombiano ${ }^{1}$, muchas son las propuestas que se vienen realizando desde diversas instancias sociales, políticas, culturales y religiosas para el acompañamiento a las víctimas. Nuestro interés es aportar también a esta situación, desde una investigación teológico pastoral, que tome en cuenta diversos ejes articuladores tales como: (1) la memoria histórica; (2) el género; (3) el desplazamiento en confrontación con los dinamismos de fe, de manera que se pueda ofrecer una respuesta integral. Este artículo se centrará en la articulación de la memoria histórica -desde sus dimensiones político, social, de género y religiosa-, con la reflexión creyente. Esta propuesta es uno de los resultados de la investigación "Lineamientos teológico-pastorales para el acompañamiento a personas en situación de desplazamiento. Un aporte desde la pastoral (sub)urbana", que constituye la segunda etapa de la investigación: "El desplazamiento forzado: un desafío a la pastoral (sub) urbana"3.

Esta investigación se nutre de los recursos documentales sobre las temáticas reflexionadas pero también de la investigación de campo realizada en la primera etapa de esta investigación ${ }^{4}$ más los datos obtenidos de una jornada de trabajo con doce mujeres desplazadas ${ }^{5}$. En

1 Por "Conflicto armado colombiano" entendemos el conflicto de más de cinco décadas que se ha vivido en Colombia. En este conflicto se han enfrentado diversas guerrillas (FARC, ELN, EPL, entre los grupos más representativos), los paramilitares (grupos ilegales que surgieron como estrategia contrainsurgente del ejército) y el Ejército colombiano. Se han intentado varios procesos de paz que han fracasado una y otra vez. Actualmente se están llevando a cabo "los diálogos de la Habana" entre la FARC y el gobierno colombiano, diálogos en los que se tienen muchas esperanzas y, actualmente, están dando frutos muy positivos.

2 Esta investigación está apoyada por la Pontificia Universidad Javeriana, según ID PRY 006010 (Marzo 2014- Septiembre 2015).

3 Esta investigación se llevó a cabo del 2011 al 2013 bajo el título "El desplazamiento forzado: un desafío para la pastoral (sub)urbana". Lo resultados de la misma pueden consultarse en: Vélez, C., Sierra, A., Rozo, C., Rodríguez, A., Camargo, A. \& Becerra, S. (2014). El desplazamiento forzado: Un desafío a la pastoral suburbana. Revista Franciscanum, 56 (161), 221-261.

4 Se trabajó con 6 varones y 9 mujeres (personas en situación de desplazamiento); 4 agentes de pastoral y 5 organizaciones que trabajan con desplazados. En esa ocasión se utilizaron las técnicas de entrevista a profundidad, grupo focal y un taller con el objetivo de sistematizar la manera como las iglesias están respondiendo a las personas desplazadas y, al mismo tiempo, las expectativas que estas personas tienen frente a las iglesias. Una descripción más completa este trabajo de campo se puede consultar en Vélez et al. (2014: 222-224. 230-232).

$5 \quad$ Esta jornada se llevó a cabo el 25 de noviembre de 2014 y en ella se realizaron tres talleres y una celebración litúrgica. Los talleres consistieron en indagar sobre los 
este artículo presentaremos, en primer lugar, lo concerniente al método, los antecedentes y la justificación de la presente investigación. En un segundo momento, presentaremos los desarrollos teóricos de las categorías aquí trabajadas. Seguidamente los resultados del trabajo de campo y, finalmente, propondremos algunas pistas de acción para una pastoral urbana que incorpore la memoria histórica en sus propuestas de acción.

\section{Precisiones metodológicas}

\subsection{El método}

El método propio de la teología es el hermenéutico porque Dios se revela en la historia, como lo afirma Dei Verbum (2000: n. 2): "El plan de la revelación se realiza por obras y palabras intrínsecamente ligadas; las obras que Dios realiza en la historia de la salvación manifiestan y confirman la doctrina y las realidades que las palabras significan; a su vez, las palabras proclaman las obras y explican su misterio", y es tarea humana, interpretar esa revelación.

Pero la interpretación es una tarea compleja porque supone comprender valores, intereses, desarrollo intelectual y experiencias tan diversas como son los individuos de cada contexto particular y de cada tiempo histórico. Por eso la pregunta que se impone en la tarea hermenéutica es: ¿qué se quiso significar con la frase, el parágrafo, el capítulo, el libro? Además hay cuatro factores que hoy contribuyen a hacer más difícil la tarea de la interpretación: (1) el surgimiento de la conciencia a la vez mundial e histórica: somos conscientes de que hoy existen muchas y muy diferentes culturas (2) el progreso de las ciencias humanas con su multiplicidad de perspectivas sobre cualquier asunto (3) la confusión reinante en la teoría del conocimiento y en la epistemología: la interpretación es precisamente un caso particular del conocimiento y, por lo tanto, la confusión que afecta al conocimiento implica una confusión en la interpretación (4) la modernidad que implica una liberación de las referencias del pasado y una exaltación del aquí y el ahora, de la practicidad inmediata, de la eficacia (Lonergan, 1994: 150).

siguientes aspectos: (1) experiencia de Dios, (2) corporeidad (3) memoria (4) género. En concreto para el tema que nos ocupa, en este artículo los dos últimos talleres arrojaron datos sobre los recuerdos que tienen de antes y después del desplazamiento y, desde su condición femenina, que cambios perciben entre las antepasadas femeninas de su familia y ellas en el horizonte del desplazamiento.

VERITAS, No 34 (Marzo 2016) 
Desde estos presupuestos asumimos que la interpretación es situada, que es apropiada por un intérprete también situado, haciendo del acto de comprender una relación de ida y vuelta entre el sujeto que interpreta y la realidad a ser interpretada. En otras palabras, en la interpretación se establece el círculo hermenéutico entre el texto, el contexto y el pretexto (Parra, 2003: 29-42) que para nuestro caso concreto se sitúa así: (1) el contexto es la realidad experimentada y descrita por las doce personas, en situación de desplazamiento, que participaron en el taller sobre memoria y género y los resultados del trabajo de campo de la primera etapa de esta investigación (2) el texto corresponde al marco teórico constituido por los documentos que fundamentan la reflexión sobre memoria histórica (3) el pretexto corresponde a nuestra intencionalidad que busca un acompañamiento integral donde se articule lo sociopolítico con lo religioso, buscando un desarrollo pleno de los destinatarios de la actividad pastoral.

Para obtener los datos del contexto se acudió a la técnica del taller grupal, una de las tantas técnicas que pueden ser usadas en las ciencias sociales para interactuar con las personas y su realidad existencial.

\subsection{Antecedentes y justificación}

El motivo que llevó a plantear esta investigación en su primera etapa, fue la pregunta que la iglesia ha de hacerse frente al fenómeno del desplazamiento y su acción pastoral. En el VI Sínodo de la Arquidiócesis de Bogotá, la preocupación por la pastoral en la ciudad se expresaba así: "En este mundo que evoluciona tan rápidamente corremos el riesgo de perder el contacto con la realidad circundante y por tanto de marchar en un camino paralelo pero no convergente con el de los hombres de hoy, a quienes la iglesia debe llevar el mensaje de salvación" (Revollo, 1998: 3). Pero no sólo pensar la pastoral urbana es difícil sino asumir los nuevos fenómenos que acontecen en las ciudades. Para el caso de Colombia, el fenómeno del desplazamiento ha transformado las ciudades porque en ellas ya no sólo habitan los pobres o marginados sino que cada día siguen llegando más personas que huyen de los campos para salvar sus vidas y engrosan considerablemente esta población marginada de las urbes. En el año 2014, el consejo noruego para los refugiados afirmaba que en Colombia hay 5.7 millones de desplazados, constituyéndose en el segundo país, a nivel mundial, con mayor número de desplazados ${ }^{6}$.

$6 \quad$ Se puede ver el reportaje en Noticias Caracol (2014). Colombia es el segundo país del mundo con más desplazados, según informe. Recuperado de 
Los resultados de la primera etapa de esta investigación concluían, entre muchos otros aspectos, que una pastoral que toma en serio el fenómeno del desplazamiento y se orienta "a los sujetos sufrientes, cuya vida se caracteriza por la liminalidad y la ambigüedad, rompe con los programas masivos, estandarizadas e inamovibles que en general ofrecen las parroquias de las grandes urbes" (Vélez et al., 2014: 248).

Dicha pastoral necesita plantearse en un contexto interdisciplinar para comprender bien la realidad del desplazamiento. Sólo se puede responder efectivamente a una situación si esta se conoce adecuadamente. Además la respuesta pastoral supone desarrollar aspectos de las personas en situación de desplazamiento que no provienen únicamente de la teología.

A nivel teológico se presentó el principio compasión misericordia, no como una categoría más sino como la categoría central para proponer una pastoral capaz "de detenerse ante los caídos en el camino" (Lc 10, 23-37) y no dejar de atender sus heridas hasta que estas sanen efectivamente. Todo esto implica y exige también, una conversión intelectual, moral y religiosa (Lonergan, 1994: 231-238) de los agentes de pastoral. Intelectual porque se hace urgente un cambio epistemológico que permita comprender la complejidad del fenómeno del desplazamiento y se quiera responder a él desde una perspectiva interdisciplinar, moral porque es imperativo ético afrontar esta realidad del país y nadie puede quedar por fuera y religiosa, porque la experiencia del Dios de Jesús ha de comprometernos con los caídos en el camino y, para la realidad colombiana, el desplazado es un verdadero herido frente al cual hemos de empeñar todas nuestras acciones pastorales para transformar su situación (Vélez et al., 2014: 256-257).

Pero se hacía necesaria una segunda etapa -lo cual es el objetivo de este artículo- para desplegar nuevas categorías que fueran centrales a la hora de responder a la realidad del desplazamiento. Concretamente, la categoría memoria histórica porque "la memoria es la condición de imposibilidad del olvido del sufrimiento de las víctimas. Es la 'memoria passionis’ de la tradición bíblica. El Dios bíblico mantiene esta memoria, las víctimas no olvidadas se conviertan en criterio decisivo para la salvación que Él otorga" (Vélez et al., 2014: 238). Este será el objetivo de los siguientes apartados.

http://www.noticiascaracol.com/nacion/colombia-es-el-segundo-pais-del-mundo-conmas-desplazados-segun-informe.

VERITAS, No 34 (Marzo 2016) 


\section{Aproximación a la categoría Memoria}

Por la centralidad que hemos señalado de la recuperación de la memoria histórica, queremos profundizar en el marco teórico que esta categoría implica. Para ello nos remitiremos en primera instancia a los aportes socio políticos sobre esta categoría. En segundo lugar introduciremos la perspectiva de género para enriquecer esta reflexión. Finalmente, abordaremos esta categoría desde la perspectiva teológica.

\subsection{Categoría memoria desde la ciencia política ${ }^{7}$}

Se entiende por memoria histórica "un relato que da sentido a un período" (Antequera, 2011: 17). Pero los relatos no se construyen desde la neutralidad. De ahí que se exija construir el relato desde un marco amplio que muestre la violencia estructural que acompaña todo proceso histórico, las situaciones políticas y económicas que la sostienen, al mismo tiempo, que las resistencias sociales y las alternativas políticas que levantan tanta persecución por parte del poder establecido. Sólo un marco amplio puede garantizar una reconstrucción de la memoria que implique a todos los miembros de la sociedad de manera que sean todos los que se empeñen en superar esa situación y velar porque no se repita nunca más. Si no se hace este esfuerzo, no hay un compromiso con el cambio y menos con la tarea de construir una historia distinta.

Hay varias maneras de hablar de memoria. Esta se ha entendido como memoria colectiva, memoria histórica y memoria emblemática. Según el Sociólogo Emile Durkheim (Rodríguez, 2015) de fines del S. XIX, existe la Memoria colectiva que consiste en un conjunto de creencias y sentimientos comunes al término medio de los miembros de una misma sociedad, que constituyen un sistema determinado que tiene vida propia. Este concepto ha sido cuestionado porque da la impresión de una conciencia que vive por encima de los individuos. Por esto Maurice Halbwaks propone una memoria colectiva como asunto que rebasa la individualidad pero no niega la subjetividad y consiste más en 'marcos sociales de memoria', es decir, una memoria construida por los individuos pero no solos sino en relación con otros, en marcos muy concretos de espacio, tiempo, lenguaje, familia, religión. Es decir, es una memoria que apela a los contextos en los que están inscritos los individuos y a partir de la estructura de los códigos culturales que comparten con otros. Así el lenguaje se convierte en el cuadro más elemental y más estable de lo que se denomina memoria colectiva (Prieto-Laya, 2011:119).

Seguimos fundamentalmente los aportes de Antequera (2011). 
Se comienza a hablar de memoria histórica, a partir de los 80s cuando surge la preocupación conceptual por develar el asunto de la memoria como ejercicio político y jurídico. Comienza así la proliferación de museos, centros de memoria, informes y demás elaboraciones que muestran la dimensión trágica de la vida sociopolítica (Antequera, 2011: 33). Pero esta recuperación no es para volver al pasado sino para determinar el futuro, por tanto, las políticas de memoria emergen como escenarios de dotación de sentido, en constante transformación, determinado por las interacciones sociales como interacciones de poder. Ante esto surgen dos posturas: los que afirman que esa historia colectiva sólo puede ser elaborada por los que han vivido esa realidad y los que comprenden la memoria como una propiedad extendida más allá de los grupos comprometidos con la vulneración de los derechos humanos en ese trozo de historia. Además introducir el concepto víctima trae nuevas implicaciones en la construcción de esa memoria histórica (Antequera, 2011: 34).

Podríamos preguntarnos si no es lo mismo memoria colectiva que memoria histórica. En principio sería lo mismo, pero el uso de la categoría memoria histórica explicita la dimensión de los efectos simbólicos e incluso psicológicos de las prácticas de sometimiento, de los conflictos. La memoria histórica supone el esfuerzo de pasar de la memoria escrita por los vencedores, a la historia que articula la parte de los vencidos. Cuando este relato se acepta ampliamente en la sociedad y se posiciona como visión hegemónica, se denomina memoria emblemática (Antequera, 2011: 34-36).

A esa memoria emblemática se le han dado diversos nombres, como por ejemplo: Doctrina de los dos demonios (Argentina, Ernesto Sabato, terror de parte de la dictadura y de la Izquierda), Nunca más (cono sur) y Memoria democrática (España). Cabe anotar que estas memorias emblemáticas suponen un proceso complejo ya que supone la adopción, por diversos actores, de núcleos propositivos comunes para evocar el pasado. Nunca un régimen de memoria logra uniformizar la evocación del pasado, o evitar que circulen interpretaciones diferentes u opuestas. Pero esto no invalida sino que incluso contribuye a su reproducción en el tiempo, organizando un debate público que sigue estando abierto para dotar de sentido el pasado y proponer nuevos horizontes para el futuro. Todo esto no evita los intentos de vulneración, sometimiento, fragmentación y desnaturalización de esas mismas memorias emblemáticas para evitar las consecuencias que se desprenden de un reconocimiento de las violencias y violaciones sufridas por las víctimas. Por tanto, supone una continua confrontación para que esos relatos estén en articulación con la verdad y asegurando la libre expresión en un marco democrático donde no se castigue la misma (Antequera, 2011: 39-41).

VERITAS, No 34 (Marzo 2016) 
En el caso colombiano el problema es cómo reconstruir una memoria emblemática cuando ni siquiera el conflicto ha terminado. Pero según Castillejo, avanzan ya procesos de consolidación de dichos relatos que merecen respuestas y posiciones críticas. En particular, a partir de la Ley de Justicia y Paz, "hay una redefinición del pasado (...) la cual contiene una serie de definiciones sobre la violencia y sobre los actores violentos, que de por sí, cambian las maneras como se ha entendido este país y que a mi modo de ver despolitizan completamente el debate" (Castillejo, 2010: 32).

Es muy valioso ver cómo se ha ido dando el proceso de confrontación entre hegemonía y articulación de la memoria histórica. Hasta el proceso de Nuremberg se concebía la legitimidad de los decretos de perdón y olvido como fórmula de garantía del futuro de paz, haciendo del silencio una imposición supuestamente legítima. A partir de la Segunda Guerra Mundial se vio la urgencia de la aplicación de los derechos humanos y el imperativo de la memoria como fundamento de la no repetición. La caída de las dictaduras en América Latina permitió explicitar la urgencia de la memoria vinculada a las víctimas y desde ahí comenzó la importancia para las ciencias sociales y la política. Surge así el posicionamiento de la memoria histórica vinculada al imperativo de garantía de los derechos a la verdad, la justicia y la reparación. Esto surge en contra de las pretensiones del nazismo y de los dictadores latinoamericanos de no ser castigados o no recordar más lo sucedido allí (Antequera, 2011:4346).

En Colombia se han configurado diversas propuestas de reconstrucción de la memoria que conviene considerar para impulsar las más adecuadas. Por ejemplo, Iván Orozco Abad (2009) propone la doctrina de los dos demonios (victimización horizontal) para el caso colombiano. Gómez Muller (2008) no coincide con Orozco porque considera que no es una interpretación correcta, sino un paradigma hegemónico. Ese modelo sitúa la violencia en la dimensión horizontal pero queda como una representación aislada de la verdad factual sin una investigación profunda de los planes de exterminio y desplazamiento intencionales, quedando el conflicto como algo dependiendo de la voluntad de los actores armados, sin desentrañar toda esa zona gris que existe en conflictos de este tipo.

El peligro que existe cuando se desarticula la memoria de la verdad factual (verdad que se puede verificar por las investigaciones judiciales y extrajudiciales) es que se caiga en el olvido y así la memoria queda como mera representación, capaz de distorsionar las relaciones reales y desubjetivar la experiencia de las víctimas y el vaciamiento político de la interpretación de los períodos que la memoria histórica se encarga de dotar de sentido. 
Otra propuesta es la del humanitarismo hegemónico que consiste en sacar la publicidad de las vidas azotadas por la guerra pero sin profundizar en el conflicto en sí, sino llamando a la solidaridad con esas vidas que se consideran sagradas y despiertan la solidaridad pero sin hacer ninguna referencia a la conciencia política y a los problemas que ocasionan tal situación. La diferencia con la propuesta de una memoria histórica con dimensión política es que las víctimas cumplen el papel ético de garantizar que en la controversia social, en las transacciones que exigen las negociaciones de paz, un sector de la sociedad mantendrá perseverantemente el sentido de la dignidad humana con relación a los crímenes del pasado. Lo que está en juego es el concepto de las políticas de la memoria que debe caracterizarse no como el enfrentamiento entre los derechos humanos y la reconciliación o la paz, sino el de la pugna entre una mirada humanitarista, que concibe a las víctimas y a los acontecimientos aislados de la estructura jurídico-política donde se producen, vía desarticulación a partir de un despojo de la vida política de las víctimas, de una mirada que se propone el desentrañamiento de los elementos que llenan los vacíos mencionados (Antequera, 2011: 59-60).

En Colombia no se puede plantear el conflicto aislado de la estructura jurídico política en la que se produce. De no hacerlo se cae en relatos del estilo, por ejemplo, de que las guerrillas existen por generación espontánea o por mera voluntad de ejercer la violencia. Por el contrario, la construcción de memoria histórica como relato que confiere sentido al periodo de conflicto y violencia sociopolítica, supone necesariamente un rescate de la mirada política que implica: a) caracterización de origen estructural y político del conflicto b) el reconocimiento de las víctimas como ciudadanos vulnerados en sus derechos pero con formas de vida y proyectos políticos cercenados que hacen parte del daño reparable más allá del daño a su vida biológica c) la construcción de un relato donde las razones para emprender los reconocimientos que autorizan las negociaciones políticas surgen de la verificación de los elementos anteriores y del comportamiento real de los actores donde se estudian los límites a las amnistías y los indultos, garantizando el derecho a la verdad sin instrumentalizarlo como argumento para negar la justicia (Antequera, 2011: 6162).

El desafío que se impone en palabras de Walter Benjamín es "la no contemplación, sino política, no fascinación, sino interpelación” (Reyes, 2006: 160) porque no se trata de saber la verdad sino de que ese conocimiento conlleve la posibilidad de involucramiento de la sociedad, ampliamente considerada, en una transformación en la que necesariamente está comprometida. Para Manuel Reyes Mate: "Recordar para que la bar- 
barie no se repita" y según Adorno "reorientar el pensamiento y la acción para que Auschwitz no se repita” (Reyes, 2006: 127).

Reconstruir la memoria historia en Colombia supone articular varias realidades. En primer lugar, articular la memoria corta con la memoria larga, que supone reconstruir todo el marco sociopolítico, cultural y económico en el que se inserta un hecho concreto. En segundo lugar, articular la victimización con la construcción democrática porque hay que clarificar el modelo de democracia. Puede ser a favor de una reducción de la memoria como dispositivo de seguridad transicional con horizonte de democracia representativa de mercado o a favor de un modelo de democracia participativa que incluye la posibilidad de la comunicabilidad de la experiencia social para el reconocimiento de los procesos de victimización que cuestionan la extensión violenta de la democracia hegemónica. En tercer lugar, como lo propone Naomi Klein, es necesario articular la victimización con la estructuración económica, con lo que se ve que la población no eligió el sistema neoliberal o acumulación de capital que, de alguna manera, legitima el exterminio a gran escala. En términos de Walter Benjamín se trata de incorporar en la memoria la cuestión de lo que pasó después de observar las consecuencias de los procesos de victimización. Pero aún más, se trata de indagar, de un lado, el ya mentado asunto de las causas estructurales del conflicto, pero más allá, el de sus consecuencias estructurales (Antequera, 2011: 66-75). En Colombia tres leyes han permitido la emergencia de políticas oficiales de memoria: (1) La Ley 975 de 2005 (Ley de Justicia y Paz) -reconoció el derecho de la sociedad a conocer la verdad y a las medidas de satisfacción para la reparación-; (2) La ley 1408 de 2010, por la cual se rinde homenaje a las víctimas del delito de desaparición forzada y se dictan medidas para su localización e identificación; (3) La Ley de Víctimas y de Restitución de Tierras de 2011 que dicta medidas de atención, asistencia y reparación integral a las víctimas del conflicto armado interno y se dictan otras disposiciones. Establece que las víctimas de antes de 1 de enero de 1985 tienen derecho a la verdad y reparación simbólica. Estableció el 9 de Abril como el Día Nacional de la Memoria y la Solidaridad con las Víctimas. Se creó el Centro de Memoria Histórica (Nacional). (A partir de ahí se han creado otros dos centros, uno en Bogotá "Centro del Bicentenario: Memoria, paz y reconciliación” y otro en Medellín "Casa de la Memoria”).

\subsection{Categoría memoria desde la perspectiva de género}

Reconstruir la memoria del conflicto armado colombiano para un nunca más pasa por la introducción de la perspectiva de género si no se quiere contribuir a estereotipos de vinculación guerra-mujeres, con una 
visión “idealizada, descontextualizada, fragmentaria y general” (Sánchez, 2011: 13), relegando a las mujeres a los lugares tradicionales donde se les ubica desde una mentalidad patriarcal, lugares apolíticos y en condición de pasividad, dependencia y subordinación.

Todos los conflictos tienen elementos que pueden ser universales como el hecho de que se enfrentan grupos antagónicos y de que persisten los imaginarios femeninos y masculinos desde los cuales se considera que los hombres van al campo de la batalla y las mujeres se quedan en casa. Pero cada conflicto es distinto y se necesita hacer esas diferenciaciones, recuperando las voces de todos los actores.

Las mujeres han sido un grupo que, muchas veces, se les ha dejado en la parte del "coro" cial. "Introducir la perspectiva de género es darle voz y poner en el centro de la historia sus testimonios, trabajando sobre ellos como posibilidad de reconstruir la historia también desde 'ese lado', considerándolas como productoras de saber y de versiones históricas que merecen ser escuchadas y validadas" (Sánchez, 2011: 15). Por supuesto, al escuchar esas voces femeninas, se descubre también la percepción de las acciones masculinas desde esas experiencias y se puede captar, con más claridad, los imaginarios o estereotipos de género que influyen en los comportamientos y decisiones. Lo que se pretende es la reconstrucción de una "memoria incluyente, es decir, una memoria que reconozca esas otras historias (entre ellas, las de las mujeres) y que, precisamente, se constituya en el lugar de la enunciación y tramitación de sus luchas hacia el futuro" (Sánchez, 2011: 14). Ese esfuerzo por reconstruir la memoria desde una perspectiva de género da la posibilidad de proponer casos emblemáticos donde la visibilización de las historias y experiencias de las mujeres estén presentes.

Para algunos no hace falta explicitar la realidad de las mujeres porque creen que la historia sólo tiene una versión. Sólo en el empeño de visibilizar a las mujeres se puede descubrir el contexto patriarcal que cuenta la historia desde su ángulo que, normalmente, corresponde al lado de los vencedores, no de los vencidos. La discriminación de las mujeres es una larga historia que se puede identificar desde el origen de las democracias modernas ${ }^{9}$. En dichas democracias el lugar de las mujeres fue

$8 \quad$ El coro es la metáfora usada por José Nun para indicar las jerarquías que atraviesan el escenario público. Como en una pieza de ópera, a unos actores se les asigna el lugar central, mientras que a sectores subalternos se les ubica en el lugar del coro (Nun, 1989).

9 Por democracias modernas entendemos aquellas que emergen luego de que en Europa se constituyera un campo, el de la opinión pública, no regulado ni por la monarquía ni por la Iglesia; y emergió lentamente el individuo como un sujeto portador de

VERITAS, No 34 (Marzo 2016) 
el de "ciudadanas pasivas y dependientes- que las hizo objeto de subordinación, violencias y discriminaciones políticas, económicas y culturales particulares. Estas discriminaciones y violencias se entretejieron con la formación de los nuevos regímenes e impregnaron las nuevas sociedades pero, por el carácter privado que se les imputó, quedaron ancladas en el silencio y la invisibilidad" (Sánchez, 2011: 17). En la década de los noventa, los movimientos de mujeres fueron conquistando lugar en el espacio público y en las constituciones de los diferentes países. Se fue pasando de considerar las violencias contra las mujeres como hechos aislados perpetrados por sujetos patológicos a considerarla en inadmisibles política y moralmente. Desde este horizonte es que se hace posible preguntarse cómo en el campo de guerra, esas violencias contra las mujeres son fruto de la mentalidad patriarcal e imperante por esta tradición histórica y ver también la gravedad de esos actos a nivel político y moral.

Ahora bien, este trabajo por incorporar la presencia de las mujeres no puede quedarse en verlas solamente como víctimas sino también en su capacidad de resistencia, liberándolas así de ese papel de sujeción que las ha caracterizado. Sin dejar de nombrar su participación en los grupos que producen esas violencias y donde se puede ver, muchas veces, la misma mentalidad de subordinación introyectada en las mujeres, aunque ocupen puestos de mando.

Para entender los cambios introducidos en las democracias modernas hay que recordar lo que se llamaba el "Antiguo Régimen"10 en que se nacía monarca o vasallo y esa situación no podía cambiarse. Los gestores de los proyectos democráticos de finales del Siglo XVIII y principios del siglo XIX imaginaban un orden social como resultado de los acuerdos entre los individuos libres e iguales. Sin embargo, en esa categoría no entraban todos. Solamente se reconocían como libres e iguales a los hombres burgueses de la época. Las mujeres, por sus diferencias biológicas, quedaron afuera o peor aún, en un no lugar, sin derecho al voto y, por supuesto, sin ni siquiera poder nombrase desde su propia mirada (Sánchez, 2011: 20). En realidad esos ideales democráticos nacieron en medio de sociedades organizadas en torno a representaciones culturales que se refrendaron políticamente, permitiendo así su pervivencia hasta el día de hoy, en algunos contextos.

derechos separado y separable de su comunidad de origen. Las democracias modernas se distinguen de las antiguas, entonces, por su énfasis en el individuo y una esfera pública (Sánchez, 2011: 17).

10 El concepto remite a la experiencia histórica francesa: luego de la Revolución Francesa, los defensores de un retorno a la monarquía y a un orden aristocrático se consideraban a favor del Antiguo Régimen (antiguo en relación con el nuevo régimen, aquel condensado en el proyecto revolucionario democrático) (Sánchez, 2011: 19). 
A las mujeres se les imputó una esencia trascendente que las presentaba como criaturas cercanas a la naturaleza, emocionales, intuitivas, arrastradas por sus pasiones, ancladas al pensamiento concreto y con una inclinación innata hacia el cuidado por los otros. Los cuerpos femeninos, asociados a una naturaleza indómita que había que conquistar, pacificar y civilizar, también bajo estos procesos fueron constituidos en objetos de regulación por parte de la política, la medicina, la Iglesia y la educación (Sánchez, 2011: 20-22).

Todas esas razones justificaron su exclusión socio política y así las mujeres quedaron constituidas no sólo como opuestas a lo masculino sino también como inferiores.

Además de los estereotipos culturales está la separación de esferas de la realidad: lo público, lo privado y lo íntimo. En las tres esferas el varón tiene un papel principal, logrando así generar una triple exclusión de las mujeres: exclusión política, subordinación social e invisibilización de las violencias. Ni siquiera su participación en la industria -cuando se hizo necesario porque los hombres marcharon a la guerra- fue tenida en cuenta como tampoco su trabajo en el hogar. Todo esto fue invisibilizado en el área de la productividad lo que creó el imaginario de las mujeres como no productivas. Y para el varón ejercer su liderazgo en las tres esferas, le fue permitida - en cierto sentido- el uso de la fuerza para que pudiera ejercer su autoridad plena. La violencia doméstica de alguna manera fue justificada como un mal necesario para contrarrestar la naturaleza indómita y pasional de las mujeres.

En los contextos de guerra, sólo el varón podría participar por su fuerza física y su frialdad sentimental y de hecho se entraba a las escuelas de formación para desarrollar más el cuerpo viril que garantizara la defensa de la Patria. Era impensable que un cuerpo débil -el de las mujeres- y lleno de afectos incontrolables pudiera forman parte de este ámbito militar.

Las luchas emprendidas por las mujeres se concentraron en primer lugar en la conquista de sus derechos civiles -el derecho al voto- y, en segundo lugar, sus derechos culturales. Pero es en la década de 1975 a 1985 - declarada por la ONU como década de la mujer- es cuando "la violencia comienza a ser denunciada, ya no como un fenómeno que ocurre sólo en la familia, sino también como una forma de discriminación y violación de los derechos humanos de las mujeres" (Sánchez, 2011: 30). Después de la conquista de varios instrumentos internacionales para reconocer que atacar la violencia contra las mujeres es defender sus derechos humanos, se reconoció que 
la violencia contra las mujeres reviste un carácter de género, es decir que es el producto de las relaciones históricamente desiguales entre hombres y mujeres que ubican a las mujeres en condición de vulnerabilidad frente a los varones. Se reconoció además que se trata de una vulneración de los derechos humanos de las mujeres, y que su ocurrencia impide el goce de los demás derechos humanos, y amplió el espectro de las violencias, desde la ocurrida en las familias hasta la producida por el Estado, incluidos los caracteres físico, psicológico, sexual o moral de las posibles agresiones. Estos instrumentos, además, conminaron por primera vez a los Estados firmantes a actuar con la debida diligencia para prevenir, sancionar y erradicar una forma de violencia que está en riesgo de ser sufrida por la mitad de la población del mundo (Sánchez, 2011: 33-34).

Durante décadas se ha justificado la violencia contra las mujeres en contextos de guerra como consecuencia del impulso sexual irrefrenado de los varones. Pero esto no es suficiente. Hay más intereses socio políticos como la violencia sexual que se toma como arma de guerra para vencer al enemigo. De hecho,

la violación sexual en un contexto de conflicto armado se enmarca en un ámbito de poder y control violento estructurado por las ideas del privilegio masculino, combinadas con las inequidades étnicas, generacionales y de clase entre las mujeres. $\mathrm{Al}$ respecto, se han identificado algunas causas para la violencia sexual contra las mujeres en estos contextos: por un lado, la intención de humillar a la comunidad de la cual es parte la mujer, y a los hombres que no 'cumplieron' con su rol de protección. Por otro lado, se identifica la conexión entre la militarización de un Estado y la violencia contra la mujer. Es importante resaltar que la violencia sexual en estos contextos tiene diferentes connotaciones, que van desde el botín de guerra hasta la intención de sembrar terror y embarazar a las mujeres de una determinada comunidad (...), en los conflictos armados la violencia sexual es utilizada contra las mujeres como un medio de castigo y represión, siendo el caso que "la utilización del poder estatal para violar los derechos de las mujeres en un conflicto interno, además de afectarlas a ellas de forma directa, puede tener el objetivo de causar un efecto en la sociedad a través de esas violaciones y dar un mensaje o lección (Sánchez, 2011: 37).

Jurídicamente se han conseguido avances en este campo para visibilizar a la mujer. El Estatuto de Roma de la Corte Penal Internacional, 1 de julio de 2002, admite que existen crímenes de violencia sexual que producen daños tan grandes, que hay que considerarlos crímenes de lesa humanidad o crímenes de guerra. Pero estas declaraciones quedan a la decisión de los gobiernos particulares quienes deben reglamentarlas para que puedan ser efectivas. 
Otras conquistas jurídicas han reconocido que las mujeres tienen que participar en la construcción de los relatos históricos. La consigna "todo lo privado es político" "11 ha permitido reconocer que lo que ocurre en el ámbito privado también forma parte de la historia humana. "Desde estos nuevos ángulos, los temas de investigación histórica -guerras, héroes, pactos políticos- se ampliaron para incorporar preguntas sobre familia, cotidianidad, poder y subjetividad" (Sánchez, 2011: 50). Así se han ido incorporando a la historia oficial las luchas de las mujeres, sus resistencias, su acción colectiva, marcadas sin embargo por esa subordinación de género que hace que esas mismas luchas partan de condiciones de desigualdad cultural, política y económica.

Uno de los medios que han contribuido a la visibilización de las mujeres en las historias del conflicto armado, han sido las Comisiones de la verdad, creadas

como herramientas para que países que habían confrontado violaciones masivas a los derechos humanos reconocieran y encararan esas atrocidades y diseñaran sólidas barreras institucionales que evitaran su repetición. Al traer a la luz pública y validar los testimonios de las víctimas, estas comisiones impugnaban los silencios o las versiones que buscaban negar la ocurrencia de hechos atroces (Comisiones de la Verdad, s.f.).

En sus inicios en estas Comisiones de la verdad no estaba presente la perspectiva de género. Ha sido un paso posterior y esto ha permitido que la violencia sexual sea vista como crimen que ha de ser punido como los demás.

Las memorias que buscan ser fuente, objeto y método de reconstrucción histórica, al estar atravesadas por la perspectiva de género son capaces de recoger estas historias propias de varones y mujeres, con las implicaciones políticas que conllevan y la capacidad de ver su significado real en contextos patriarcales, aún vigentes. Es en el campo de la memoria donde las personas construyen hilos explicativos para entender el por qué, el cómo, el para qué se propició un hecho. Las memorias de las víctimas asignan a los actores principales distintos grados de participación y evalúan moral y éticamente sus decisiones. Las memorias se convierten en un tamiz desde el que los actores se juzgan y juzgan a los demás, toman decisiones y son fuerzas históricas que mueven a individuos y colectivos a actuar de determinada manera. La memoria permite también dar lugar a los sentimientos y emociones, explicitando así la economía moral de los actores que es tan importante como la economía política. La me-

11 Lo personal es político fue uno de los eslóganes más característicos del movimiento feminista en los años sesenta y setenta.

VERITAS, No 34 (Marzo 2016) 
moria también, se convierte en fuente de investigación que invita a preguntar de dónde surge está memoria, qué otras memorias impugna, qué objetivos pretende, entre otros aspectos (Sánchez, 2011: 53).

La recuperación de la memoria se convierte en un método diferente a las entrevistas o encuestas. Como método, trabajan no sólo los recuerdos en clave colectiva, sino también la relación entre reminiscencia y espacio (mapas); memorias y cuerpo (mapa del cuerpo); y memorias y proyectos y agendas de futuro (colcha de retazos) (Sánchez, 2011: 54).

En el caso concreto de recuperar la historia de las mujeres hay que tener en cuenta algunos aspectos como el pudor que se ha manejado frente al sexo. Este hace que muchas violaciones no se denuncien porque no solo se visibiliza un hecho que se considera del ámbito privado sino que se estigmatiza a quien lo padeció porque de alguna manera, encarna el honor perdido de la familia o la culpa por haber contribuido a la pérdida de ese honor, aunque las mujeres hayan sido, efectivamente, las víctimas.

Otro aspecto es que las mujeres casi siempre hablan de lo que le aconteció a sus hijos, esposos y pocas veces de lo que les sucedió a ellas y a sus cuerpos. Sin darse cuenta, mantienen ese rol de estar siempre al servicio de los otros y no ser capaces de nombrarse ellas mismas. Además a la hora de tomar la vocería frente a un colectivo, casi siempre dejan que sean los varones los que tomen ese liderazgo. No obstante, el hecho de las mujeres tener que buscar a sus hijos desaparecidos, por ejemplo, o tener que seguir adelante con los hijos que les quedan después de la guerra, las sitúa en el espacio público y, de alguna manera, comienzan a tomar un papel más protagónico que les permite situarse en el centro de los relatos de memoria. En los varones, desde esta perspectiva de género, se puede observar que se recriminan más el no haber sido los protectores o defensores de su familia que los mismos hechos que se han vivido o cómo han afectado al resto de la familia.

Tomarse en serio la reflexión sobre género hace indagar la realidad con preguntas de este tipo (Sánchez, 2011: 64-65): ¿Qué tipo de sufrimiento infligieron los actores armados a los cuerpos femeninos y cuál a los cuerpos masculinos? ¿Fue similar? ¿Fue distinto? ¿El actor armado desplegó violencia sexual? Si sí lo hizo, ¿en qué contextos? ¿Para qué? ¿Qué buscaban? ¿Contra quién la ejercían? ¿Qué tareas desempeñan las mujeres y los hombres en las filas armadas? ¿Son las mismas o, por el contrario, hay una división de tareas? ¿¿Cómo afrontan las mujeres los eventos traumáticos? ¿Cómo lo hacen los hombres? ¿Hay especificidades por género? ¿Con qué recursos cuentan los hombres para afrontar los hechos traumáticos? ¿Con qué recursos cuentan las mujeres? ¿Son los mismos recursos? ¿Las discriminaciones fundadas en criterios de género 
ponen en posición de desventaja a las mujeres? Si es así, ¿cómo se manifiesta esa desventaja? ¿Cómo y qué recuerdan los hombres? ¿Cómo y qué recuerdan las mujeres? ¿Recuerdan de la misma manera? ¿Qué nos dicen esas distintas formas de recordar de hombres y mujeres sobre los arreglos de género imperantes?

La memoria histórica, por tanto, tiene género y es importante tener la intencionalidad de rememorar con esa visión para que puedan salir esos imaginarios y, a partir de ellos, se reconozca las construcciones culturales vigentes pero también se trabaje por su transformación. En este último sentido hay que velar porque a la mujer tampoco se le encasille en la violencia sexual y sólo se le reconozca como víctima si ha sufrido ese tipo de violencia, sino que se le considere desde sus diferentes posibilidades y cómo transita en diferentes roles, dependiendo del momento en que se encuentre. Las mujeres pueden ser víctimas, resistentes y combatientes y, en ese sentido, la mirada de género debe recorrer todos esos ámbitos donde está presente. El desafío que sigue pendiente es construir memorias colectivas y emblemáticas, atravesadas por la perspectiva de género.

\subsection{Categoría memoria desde una perspectiva teológica}

Johann Baptist Metz (2007) desarrolla esta categoría desde la perspectiva teológica aunque su contexto es distinto al nuestro ya que la pregunta que mueve su investigación es: ¿Cómo hacer teología después de Auschwitz?, pero esta misma pregunta podemos hacerla para el contexto colombiano: ¿cómo hacer teología en Colombiano un país con más de 5 millones de víctimas del conflicto armado?

Metz parte del sufrimiento que padecen las víctimas inocentes, preguntándose: ¿Cómo Dios permite el sufrimiento de las víctimas inocentes? o ¿cómo creer en un Dios bondadoso, un Dios amor ante el hecho del mal y la injusticia que padecen personas inocentes? No acepta una de las respuesta que se han dado a estas preguntas, la de Dios está sufriendo en esas víctimas porque esta pregunta crea un problema mayor: si Dios está sufriendo con las víctimas, ¿a quién acudir frente a este sufrimiento absurdo? ¿cómo explicar razonablemente esta realidad? Por eso incursiona en la imagen de Dios que se puede percibir en la tradición de Job, la teología negativa de los profetas, la sabiduría apocalíptica y los motivos del reino de Dios y el seguimiento para dar una respuesta más adecuada.

El primer paso que Metz propone es dejar de pensar en una visión idealista de la historia donde sólo se reconoce el progreso y los logros humanos -tentación moderna propiciada por lo que él llama amnesia cultural- y propone la categoría memoria passionis, es decir, la rememora- 
ción del sufrimiento ajeno, integrándolo a una visión real de la historia, capaz de presentar no sólo el progreso sino también el sufrimiento y la injusticia que padecen tantas personas en el mundo. Busca mantener la macro-narración de la pasión de la humanidad. Supone una visión apocalíptica en el sentido del significado de la palabra apocalíptica como desvelación, donde la desvelación del rostro de las víctimas es el antídoto que libra de una historia inmisericorde con los débiles, en la cual sólo se registra el triunfo de los vencedores (Metz, 2007: 68). La memoria passionis exige hablar de humanidad y solidaridad, de opresión y liberación, protestar contra la injusticia que clama al cielo y combatir la pobreza destructora (Metz, 2007: 93).

Metz propone asumir la racionalidad anamnética. Esta supone la memoria del sufrimiento de los inocentes, la protesta ante esta situación y la búsqueda de su transformación. La cultura anamnética es la dote del espíritu judío (Metz, 2007: 52) ${ }^{12}$. De ahí que el cristianismo nace como comunidad de memoria y narración ${ }^{13}$ de un acontecimiento salvífico, primero, en el pueblo de Israel y, segundo, en el acontecimiento Cristo, cuya primera mirada se dirigió al sufrimiento ajeno (Metz, 2007: 70).

Esta propuesta puede ser universal porque su fundamento reside en la "autoridad de los que sufren" (Metz, 2007: 111) ya que la realidad de sufrimiento puede ser constatada por todos y exige una respuesta. Esto es punto de encuentro de la pluralidad cultural y religiosa en la que vivimos, porque se apoya en la dignidad de todo ser humano, que exige su reconocimiento y sus derechos fundamentales. Bíblicamente el texto de Mateo 25, sustenta esta autoridad ya que el criterio de comunión definitiva con Dios está en la solidaridad afectiva y efectiva frente al dolor de los demás.

12 El autor considera que si Israel aporta a Europa la herencia anamnética (entendida como compassio), Grecia le aporta la curiosidad teórica y Roma el pensamiento estatal y jurídico republicano (Metz, 2007: 168).

13 La narración se propone como categoría mediadora para un diálogo orientado a la experiencia (...) Además la narración tiene mayor virtualidad comunicativa que el lenguaje argumentativo de la metafísica clásica, desvinculado de todo sujeto y que el lenguaje científico de la racionalidad occidental (...) El problema actual consiste en que muchas veces la narración se ha cambiado por el lenguaje discursivo. El primero permite un diálogo intercultural y una narración de la verdad en un contexto plural. El segundo busca ser el ganador y, por tanto no da cabida a la pluralidad. No se puede olvidar que el cristianismo parte de narraciones fundantes irrenunciables, experiencias que han de ser comunicadas y que mantienen su carácter histórico. Si todo esto se quitara, pasaría a ser una comunidad fundada en el dogma y los ritos, perdiendo toda posibilidad de intercambiar experiencias que son las que engendran y generan la fuerza del seguimiento. (Metz, 2007: 239.242.244).

VERITAS, No 34 (Marzo 2016) 
Al contrastar con el Dios revelado en las Escrituras puede descubrirse que el Dios de Abraham, Isaac y Jacob, es el mismo Dios del lamento de Job (Metz, 2007: 21). Por tanto, las imágenes bíblicas no sólo hablan del Dios amor sino del Dios que se implica en el sufrimiento humano y busca su transformación. Tanto el Dios del Éxodo como el Dios de Jesús, muestran con claridad esa acción divina para cambiar las situaciones:

Dijo Yahvé: He visto la aflicción de mi pueblo que está en Egipto, y he oído su clamor a causa de sus exactores; pues he conocido sus angustias, $y$ he descendido para librarlos de mano de los egipcios, y sacarlos de aquella tierra a una tierra buena $\mathrm{y}$ ancha, a tierra que fluye leche y miel, a los lugares del cananeo, del heteo, del amorreo, del ferezeo, del heveo y del jebuseo. El clamor, pues, de los hijos de Israel ha venido delante de mí, y también he visto la opresión con que los egipcios los oprimen. Ven, por tanto, ahora, y te enviaré a Faraón, para que saques de Egipto a mi pueblo, los hijos de Israel (Ex 3, 7-10).
Vino a Nazaret, donde se había criado; y en el día de reposo entró en la sinagoga, conforme a su costumbre, y se levantó a leer. Y se le dio el libro del profeta Isaías; y habiendo abierto el libro, halló el lugar donde estaba escrito: El Espíritu del Señor está sobre mí, por cuanto me ha ungido para dar buenas nuevas a los pobres; me ha enviado a sanar a los quebrantados de corazón: a pregonar libertad a los cautivos, y vista a los ciegos; a poner en libertad a los oprimidos; a predicar el año agradable del Señor (Lc 4,16-19)

Esta manera de comprender la implicación del Dios bíblico en la realidad humana convoca a lo que Metz llama mística de ojos abiertos ${ }^{14}$. Para el cristianismo, la paz y la felicidad que proclama, no es independiente de la solidaridad anamnética que se exige con las víctimas, de la memoria passionis, como ya se ha señalado. Lamentablemente en la experiencia cristiana ha pervivido una anamnesis cultual que, en muchas ocasiones, se ha vaciado de la anamnesis histórica haciendo del culto una realidad ajena a la historia (Metz, 2007: 83).

Concretamente la alianza de Israel con su Dios se funda en que en medio de sus sufrimientos ellos clamaron a Dios y él irrumpió en sus vidas. De la misma manera, el clamor de Jesús en la cruz hace posible la cercanía de Dios. Sin estos datos, el júbilo pascual carecería de sentido, de encarnación, de historia y sería solamente un "mito de triunfadores" (Metz, 2007: 107). El cristianismo incorpora, por tanto, en su esencia esa

14 La mística de ojos abiertos salva de la desaparición del yo en un universo desprovisto de sujetos. Supone una alianza mística entre Dios y el ser humano que consiste en esa pasión por Dios que se experimenta y acredita como com-pasión, como mística de ojos abiertos (Metz, 2007: 168).

VERITAS, No 34 (Marzo 2016) 
"compassio"15 con los que sufren. Una compassio que está muy bien relatada en la Parábola del Buen Samaritano y que supone la irrupción del sufrimiento del otro en la propia vida.

La compassio tiene grandes posibilidades de acción para Metz. En primer lugar, puede proponer una nueva política de paz que parte de tomar en cuenta el sufrimiento de todos los implicados en el conflicto, por tanto, el sufrimiento de los enemigos. En segundo lugar, la compassio puede contribuir a una nueva política del reconocimiento no de los iguales sino precisamente de los otros excluidos y olvidados, rompiendo así la lógica del mercado, el intercambio y la competencia. En tercer lugar la compassio reivindica el principio de la elemental igualdad de todos los seres humanos, de ahí la propuesta de la autoridad de los que sufren que obliga a todos los seres humanos con anterioridad a cualquier consenso y no puede ser soslayada o relativizada por cultura ni religión alguna y mucho menos por la Iglesia. En cuarto lugar, la compassio protesta contra el pragmatismo político que se desentiende de la rememoración del sufrimiento y se vuelve más ciego en el ámbito de la moral. Se constituye en una incitación a una política de la memoria que evite construir una felicidad sobre el despiadado olvido de las víctimas. Finalmente, la compassio constituye una base inigualable para la construcción del ecumenismo, realidad que hoy no es solamente religiosa sino también política por la fuerza que va teniendo lo que hoy se está llamando "la guerra de las religiones" (Metz, 2007: 169-178).

La tentación que ha tenido el cristianismo es cambiar el sufrimiento por el pecado y anunciar una redención a ese pecado y no una liberación del sufrimiento (Metz, 2007: 165). Por eso su propuesta de una nueva teología política asume el sufrimiento de las víctimas inocentes y busca hablar de Dios desde ese horizonte. Otra tentación ha sido tener en la Iglesia exceso de memoria dogmática y poca memoria del sufrimiento de las víctimas. Posiblemente por eso la autoridad dogmática que el cristianismo anuncia está teniendo tan poca relevancia, porque se aleja de la oportunidad de anunciar la autoridad de Dios como autoridad de los que sufren (Metz, 2007: 195).

Las consecuencias de proponer la racionalidad anamnética en el actual mundo regido por una racionalidad científica, se sitúan en el ámbito de lo que aporta el a priori del sufrimiento. Con este se libra al ser hu-

15 Metz utiliza la palabra latina "compassio" porque quiere evitar equívocos con la palabra "compasión". Para él, compassio significa no una vaga simpatía experimentada desde afuera o desde arriba, sino como com-pasión, como percepción participativa y comprometida del sufrimiento ajeno, como activa rememoración del sufrimiento de los otros (Metz, 2007: 167). 
mano de ser considerado un simple fragmento de la naturaleza no del todo desentrañado por medio de experimentos biotecnológicos y se le reconoce su capacidad de añoranza, de estar constituido por un pasado que no es sólo progreso sino también lucha y sufrimiento. Además el $a$ priori del sufrimiento cuestiona de antemano los resultados de la ciencia y la técnica y de las teorías económicas y políticas que no se preocupan por la asimetría existente en las condiciones de posibilidad de los seres humanos y las convoca a tener estos presupuestos en la construcción de una ética global. Además la memoria passionis expuesta como propuesta de una teología política (pública) convoca a superar la dialéctica entre la memoria y el olvido, haciendo que la memoria sea una exigencia ética ineludible. Permite, también, que el hablar sobre Dios no se quede en un plano trascendental sino que asuma la historia humana de sufrimiento y se coloque en el ámbito humano de la pregunta escatológica que nunca es concluida porque de serlo, no se estaría hablando del Dios revelado por Jesús que excede nuestras coordenadas históricas y mantiene la tensión entre esta historia humana y la promesa de una salvación definitiva (Metz, 2007: 227-220).

Metz reconoce en las iglesias pobres del Tercer mundo una concreción de un cristianismo peligroso porque en ellas se ha entendido la fidelidad a Cristo como liberación de los más pobres, exponiéndose a los peligros que ello conlleva (Metz, 2007: 146). Precisamente esta referencia a las iglesias del tercer mundo, invita a contextualizar todo lo aquí expuesto en las situaciones concretas que atraviesan estos pueblos y, para el caso que nos ocupa, la realidad del desplazamiento y lo que esto debe significar para la experiencia cristiana.

\section{La recuperación de la memoria histórica en los sujetos que su- fren el desplazamiento}

Una de las tareas que se han visto necesarias para ayudar a las víctimas del desplazamiento forzado es la recuperación de los sucesos que acontecieron no para mantener la atención en los momentos dolorosos sino para integrarlos a la propia vida, aceptarlos, denunciarlos, perdonarlos y superarlos. No se puede utilizar la expresión perdón y olvido, porque esto sería impunidad. El perdón requiere afrontar los hechos y llamarlos por su nombre. El victimario ha de reconocer el mal que impartió y la víctima tiene el derecho de ser reparada por ello. Sólo entonces el perdón puede tener lugar. El ejercicio de la memoria histórica contribuye a recomponer los hechos, no dejar que queden en la impunidad y exigir una reparación adecuada (Grupo de Memoria Histórica, 2009). 
De ahí que en los datos que se pudieron recoger con las diversas técnicas señaladas al inicio de este artículo (notas 4 y 5 ) podemos sistematizarlos con base en tres objetivos:

(1) Comprender el proceso de la memoria en sus procesos de reconstitución como personas

(2) Ver el antes y después del desplazamiento

(3) La realidad que experimentan las mujeres en dos sentidos: la diferencia que ven entre ellas y sus antepasadas y las consecuencias que, por su condición de mujer, han tenido que afrontar en la realidad del conflicto armado.

Ante la primera cuestión, las personas participantes presentaban una doble experiencia. Todas concuerdan en que poder contar su historia las lleva a liberarse del dolor que durante mucho tiempo tienen que mantener en silencio y les permite liberar todos los sentimientos de odio, rencor, desprecio que sienten frente a los enemigos. Pero, al mismo tiempo, ese dolor que llevan, quieren olvidarlo porque no les deja vivir el presente con alegría y les condiciona para restablecer su vida. Sienten una fuerte presión social para no decir que son desplazados porque esto les impide tener posibilidades de trabajo y que otras personas puedan fiarse de ellos.

Por otra parte, es precisamente recordando su condición de desplazados que pueden conseguir ayudas estatales, de ahí, que para unos esta realidad se convierte en la única posibilidad de subsistencia y, según los mismos participantes expresaban, algunas personas se quedan explotando esa posibilidad y no salen adelante de otra manera.

Hablar de lo que les pasó no resulta una experiencia fácil. Por eso las técnicas del dibujo son de gran ayuda para liberar todos sus sentimientos. Tanto en los dibujos que las participantes hicieron como en el comentario a fotografías que se les presentaron y se les pidió comentar, los participantes pudieron expresar el miedo en el momento del desplazamiento (identificándose con imágenes que expresaban miedo), la realidad que habían dejado (los dibujos que hacían remembranza de las características del campo) y sus dificultades para hacerse una vida nueva en las grandes ciudades (edificios, caos, armas, etc.).

Una de las técnicas más interesantes fue la que se refería a mostrar las cicatrices de su cuerpo y a través de ellas expresar los dolores que han sufrido a lo largo de sus vidas. Esto contribuyó a encontrarse con su propia persona (nunca antes se habían observado a sí mismas en ese sentido) y a recorrer cada una de las cicatrices que tienen una historia que algunas ya habían olvidado. También otra técnica empleada la de escribir los sentimientos que le suscita pensar en la experiencia del desplazamien- 
to y, por otra parte, escribir los sentimientos que las han fortalecido para superar la situación. Al recuperar la lista de todos estos sentimientos las personas participantes descubrían la fuerza de la dimensión afectiva en las experiencias de su vida y como cada sentimiento negativo, podía tener un sentimiento positivo capaz de transformar el sentimiento negativo.

En el segundo aspecto sobre el antes y el después del desplazamiento, se observó en los participantes una posible idealización de su pasado al contrastarlo con su presente. Lo que se veía claro era que antes tenían los medios básicos de subsistencia: techo, comida, naturaleza, familia, tradiciones culturales. Al llegar a la ciudad todo se transforma. Se siente miedo, soledad, mucho cemento, y toca comprar todo. En el campo, la naturaleza les ofrece de manera gratis los alimentos que tienen sembrados y que comparten con los vecinos generosamente.

Pero también en la ciudad encuentran aspectos positivos: la posibilidad de huir de los grupos armados o de otras circunstancias que les causan el desplazamiento y encontrar gente solidaria que les han brindado ayuda. Aunque algunas veces, tienen que continuar huyendo dentro de la misma ciudad porque al lugar que llegan encuentran personas de los grupos contrarios, de los que hay que seguir cuidándose. Para las mujeres, el llegar a la ciudad las ha librado también de la violencia intrafamiliar, en los casos en que vienen sin el marido. No obstante, los estereotipos de género hacen que las mujeres consciente o inconscientemente busquen otra pareja y no es extraño que vuelvan a ser víctimas de la nueva pareja. Especialmente, los jóvenes no quieren volver al campo porque la ciudad han encontrado posibilidad estudio y de trabajo.

El tercer aspecto sobre la realidad de las mujeres en el antes y después del conflicto, va en la línea de lo que ya se relató en el sentido de la independencia que empiezan a ganar las mujeres al llegar a la ciudad. Inclusive algunas relataban la inversión de papeles que se ha dado entre ellas y sus maridos. En la ciudad ellas consiguen trabajo con más facilidad y pueden convertirse en las proveedoras familiares. Aunque lamentablemente, en muchas ocasiones, ni siquiera esta condición de independencia y de proveer el sustento económico, las libera del maltrato de sus maridos que, muchas veces justifican, por ser la cabeza de la familia.

Al comparar la vida de las mujeres actuales con las de sus antepasadas se veían contrastes muy interesantes. En primer lugar, las que no habían padecido de cerca la violencia social, si habían padecido la violencia intrafamiliar. Es verdad que gozaban de cierta tranquilidad al tener las condiciones básicas para vivir y criar a sus hijos. Además el entorno se facilitaba para la vivencia de valores como la honradez, la generosidad y la responsabilidad, todo ello alimentado por la vivencia católica que era muy común en los campos colombianos. En lo que todas coincidían 
también era que sus antepasadas no habían ido a la escuela. Contrastando con la situación de las mujeres actuales, la mayoría había cursado los estudios primarios pero, por el estereotipo patriarcal, no percibía la necesidad de estudiar más ya que su destino era casarse y tener muchos hijos. La violencia que han padecido, les ha hecho comprender la falta que hace una mayor preparación intelectual y por eso quieren brindársela a sus hijas. Sin embargo, las carencias económicas que sufren en la actualidad, les impide muchas veces realizar sus sueños.

Con respecto a la violencia intrafamiliar se perciben cambios y se comienzan a exigir los derechos de no ser maltratadas y de denunciar los abusos cometidos contra ellas. Aunque en los trabajos grupales, algunas expresaban haber sido víctimas de violencia sexual, también comentaban la dificultad de denunciar este tipo de abusos por temor a ser rechazadas por sus familiares más próximos y a ser estigmatizadas por la sociedad en general.

Estos datos contribuyen a mostrar que las personas víctimas de desplazamiento reconocen el bien que les hace tener la oportunidad de narrar los hechos que vivieron y se disponen a participar de los talleres y otras actividades que se les proponen porque saben que a través de esto, se liberan de sus sufrimientos y va encontrando caminos para reconstruir su vida. En la celebración litúrgica con la que se terminó el encuentro, las mujeres agradecieron la experiencia vivida y dejaron ver cómo su fe la sigue sosteniendo y, en muchos momentos, es su principal motor para seguir adelante.

\section{A modo de conclusión: hacia una pastoral que incorpore la re- cuperación de la memoria histórica}

El recorrido que hemos hecho hasta aquí nos ha permitido ver la centralidad que la recuperación de la memoria histórica tiene en la superación del conflicto y los efectos positivos que trae para la sanación integral de las víctimas. Por eso la propuesta de pensar una Pastoral urbana que responda de manera más eficaz a la situación del desplazamiento, pasa por la articulación de aquellos elementos que pueden propiciar una mejor respuesta a lo que dichas personas esperan de las iglesias.

Dos elementos abren la puerta para la búsqueda de esta articulación. Primero, como afirma Metz, la experiencia cristiana es una experiencia de la memoria: de la liberación de Egipto para el pueblo de Israel y del misterio pascual para el discipulado misionero que buscan vivir sus seguidores. Y, segundo, la fe continua siendo un elemento central en la vida de las personas en situación de desplazamiento, aunque algunas veces no encuentren la respuesta adecuada en las iglesias o tengan mo- 
mentos que, por la dureza de las situaciones vividas, se rebelen contra Dios y renieguen de su fe.

El haber indagado sobre la categoría memoria desde la dimensión sociopolítica exige a la pastoral urbana y, en realidad a toda la pastoral eclesial, dejar las posturas supuestamente 'neutras' y ser capaces de tener una conciencia crítica suficientemente informada para acompañar a las personas en situación de desplazamiento, poniéndose de su lado y denunciando todo discurso hegemónico que pretende domesticar la historia vivida e invisibilizar las estructuras de poder que producen y mantienen la situación de conflicto.

Desde el punto de vista teológico la categoría memoria supone una exigencia ética que las iglesias no pueden dejar de lado. La voz de las víctimas no puede ser silenciada y de la capacidad de escucharla y de responder a ella, depende que la pregunta por la justicia de Dios frente al dolor humano sea respondida.

La categoría memoria desde la perspectiva de género también despierta a la exigencia ética de responder de diferente manera a la violencia sufrida por los varones y las mujeres. Sin duda todos son víctimas con igual valor moral. Sin embargo, al introducir la perspectiva de género se puede responder no solamente a aquella violencia pública sino también a la violencia del ámbito privado que casi siempre la padecen, en mayor proporción, las mujeres.

Con estos presupuestos señalados podemos trazar algunas líneas de acción que consideramos imprescindible, introducir en la pastoral de acompañamiento a las personas en situación de desplazamiento. En primer lugar, comprender que no es una tarea que pueda realizarse en solitario. Mientras las iglesias no sean capaces de articular fuerzas entre ellas y con la sociedad civil, su eficacia se limita al ámbito religioso que podríamos llamar desencarnado porque no toma en cuenta la integralidad de las personas y supone una vivencia de la fe ajena a toda la realidad.

Articularse con otras instancias supone también mantener una conciencia crítica y una postura más clara frente al conflicto y a los actores inmersos en él. Sin duda, no es posible tener una única visión pero sí hay un criterio de discernimiento Irrefutable: el evangelio siempre se pone del lado de las víctimas y busca su curación y liberación integral. La evangelización no puede estar completa sino tomar en cuenta todas las dimensiones de la persona ${ }^{16}$.

16 La Exhortación Apostólica Evangelii nuntiandi de Pablo VI, sigue siendo un documento obligado para una acción evangelizadora que busca responder a los desafíos de hoy, liberándose de falsos espiritualismos.

VERITAS, No 34 (Marzo 2016) 
La liturgia eucarística, principalmente, ha de estar atravesada por mantener la memoria de las víctimas. En un país como Colombia con un número tan elevado de personas en situación de desplazamiento y de víctimas del conflicto armado, sorprende constatar que esa situación no parece acompañar la liturgia eclesial. Esto denuncia profundamente la separación entre fe y vida que se vive tantos contextos eclesiales, acercándose más a un culto vacío que al culto que agrada a Dios: "Este es el ayuno que yo quiero, soltar la cadenas injustas, desatar los lazos del yugo, dejar en libertad a los oprimidos y romper todos los yugos; compartir tu pan con al hambriento y albergar a los pobres sin techo; cubrir al que veas desnudo y no despreocuparte de tu propia carne" (Is 58,6).

Según se vio en la categoría memoria desde el aspecto sociopolítico, la recuperación de la memoria se traduce en monumentos, informes, símbolos, etc., buscando con ello que la historia lo olvide y no suceda nunca más. La Eucaristía, tendría que ser ese memorial que no deje olvidar la situación que se ha dado en el país para que nunca se repitan esas atrocidades.

La categoría género como también ya se anotó, hace tomar consciencia de las diferentes concreciones de la violencia según la persona, sea varón o mujer. En este sentido, las iglesias tienen que hacer un trabajo muy arduo para incorporar esta perspectiva no sólo en este aspecto del desplazamiento, sino en toda su realidad eclesial. Sin embargo, existen muchos miedos en el ámbito eclesial y muchos prejuicios frente a esta categoría porque se teme que llegue a borrar las identidades sexuales. No se puede negar la perplejidad que esta nueva situación causa y que aún, en ámbitos sociales, precisa de mayor integración, asimilación y aseguramiento de los derechos humanos para todas las personas. Pero el evangelio no tiene por qué huir de las dificultades, por el contrario, tendría que estar en primera fila buscando asegurar la vida para todos y todas, por encima de imaginarios y estereotipos sociales.

Si las iglesias quiere lograr una pastoral de acompañamiento a las personas en situación de desplazamiento ha de hacerse preguntas de este tipo: ¿de qué manera se ha incorporado la categoría memoria en sus líneas de acción? ¿han preguntado a Dios sobre el sufrimiento de estas víctimas inocentes? ¿han incorporado esta realidad en la narración de la experiencia cristiana que ha de ser comunicada a las generaciones futuras? ¿de qué manera se les reconoce a estas víctimas del desplazamiento la "autoridad de los que sufren" como punto de partida de cualquier valoración moral? ¿son capaces de mantener esta memoria para que no se repita nunca más? ¿cómo hablar de Dios después del fenómeno del desplazamiento que ha padecido Colombia con más de 5 millones de desplazados? ¿en qué ha cambiado la anamnética cultual en un país con 
un fenómeno de desplazamiento de esa magnitud? ¿qué imagen de Dios acompaña la pastoral de las personas en situación de desplazamiento: un Dios de canto o un Dios de clamor? ¿qué "narraciones" de fe se han construido para mantener las memoria de las víctimas?

Estas y muchas otras preguntas llevarían a una trasformación pastoral que efectivamente se sitúe en el corazón del conflicto social y quiera ofrecer una respuesta.

Porque la vida cristiana promueve el perdón y la reconciliación ha de tomarse muy en serio los pasos previos o las mediaciones adecuadas que permitirán conseguir esos procesos. Lo expuesto aquí es un esfuerzo por pensar la situación, despertar la conciencia eclesial y promover una acción pastoral encarnada en el aquí y ahora de la realidad colombiana que tantos desafíos nos presenta. De la fidelidad al evangelio de Jesús, a su praxis de liberación y a la encarnación de su mensaje en la historia de cada momento presente, dependerá que el Dios que se anuncie pueda ofrecer una respuesta adecuada a tantos millones de colombianos que resisten, trabajan y entrega su vida en la defensa de los derechos y la restitución de las víctimas.

\section{REFERENCIAS}

-Antequera, J. (2011). Memoria Histórica como relato emblemático. Consideraciones en medio de la emergencia de políticas de memoria en Colombia. Recuperado del sitio web de Pontificia Universidad Javeriana, de http://www.javeriana.edu.co/biblos/tesis/politica/tesis491.pdf

-Castillejo, A. (2010). Iluminan tanto como oscurecen: de las violencias y las memorias en la Colombia actual. En E. Barrero \& J. Salas (Eds.), Memoria, silencio y acción psicosocial. Reflexiones sobre por qué recordar en Colombia (págs. 2160). Bogotá: Ediciones Cátedra Libre/Fundación Manuel Cepeda/Fundación Mundos Posibles.

-Comisiones de la Verdad. Recuperado de http://www.truthcommission.org/index.php?lang=en

-Concilio Vaticano II (2000). Constitución dogmática Dei Verbum. (Segunda edición). (L. Amigo \& R. Herrera, Trads.) Madrid: BAC.

-Gómez, A.(2008). La reconstrucción de Colombia. Escritos politicos. Medellín: La Carreta Política.

-Grupo de Memoria Histórica (2009). Memorias en tiempo de guerra. Repertorio de iniciativas. Bogotá: Punto Aparte Editores.

-Lonergan, B. (1994). Método en teología. Salamanca: Sígueme.

-Metz, J. B. (2007). Memoria passionis. Una evocación provocadora en una sociedad pluralista. Santander: Sal Terrae.

-Noticias Caracol (2014). Colombia es el segundo país del mundo con más desplazados, según informe. Recuperado de 
http://www.noticiascaracol.com/nacion/colombia-es-el-segundo-pais-delmundo-con-mas-desplazados-segun-informe

-Nun, J. (1989). La rebelión del coro: estudios sobre la racionalidad politica y el sentido común. Buenos Aires: Ediciones Nueva Visión.

-Orozco, I. (2009). La justicia transicional en tiempos del deber de memoria. Bogotá: Tesis, Uniandes.

-Pablo VI. (1975). Exbortación Apostólica Evangelii nuntiandi Recuperado de http://w2.vatican.va/content/paulvi/es/apost_exhortations/documents/ hf_p-vi_exh_19751208_evangelii-nuntiandi.html.

-Parra, A. (2003). Textos, contextos, pretextos. Teología fundamental. Bogotá: Pontificia Universidad Javeriana, Facultad de Teología.

-Prieto-Laya, G. (2011). Pertinencia del concepto de memoria cultural en el marco de la teoría sociológica. De Emile Durkheim a la escuela de Chicago. Santiago (126), 115-123.

-Recordar y narrar el conflicto. Herramientas para reconstruir memoria histórica. Disponible en: http://www.mappoea.net/documentos/iniciativas/Memoria_Historica.pd f. (Acceso en 8 abril 2015).

-Revollo, M. (1998). Palabras pronunciadas en el contexto de la inauguración del VI Sínodo. En Arquidiócesis de Bogotá, Declaraciones sinodales. Plan Global de Pastoral 1999-2008. Bogotá: Publicaciones de la Arquidiócesis de Bogotá.

-Reyes, M. (2006). Medianoche en la bistoria. Comentarios a las tesis de Walter Benjamin "Sobre el concepto de historia". Madrid: Trotta.

-Rodríguez, A. (2015). Una aproximación a la categoría memoria. Relatoría no publicada presentada al grupo de investigación, Pontificia Universidad Javeriana, Bogotá, Colombia.

-Sánchez, G. (Coord.) (2011). La memoria histórica desde la perspectiva de género. Conceptos y herramientas. Bogotá: CNRR-Grupo de Memoria histórica.

-Vélez, C., Sierra, A., Rozo, C., Rodríguez, A., Camargo, A. \& Becerra, S. (2014). El desplazamiento forzado: Un desafío a la pastoral suburbana. Revista Franciscanum, 56 (161), 221-261.

Sumario: Introducción; 1. Precisiones metodológicas; 1.1. Método; 1.2. Antecedentes y justificación; 2. Aproximación a la categoría memoria; 2.1. Categoría memoria desde la ciencia política; 2.2. Categoría memoria desde la perspectiva de género; 2.3. Categoría memoria desde la perspectiva teológica; 3. La recuperación de la memoria histórica en los sujetos que sufren el desplazamiento; 4. A modo de conclusión: hacia una pastoral que incorpore la recuperación e la memoria histórica; Referencias. 